\title{
The change of T-wave on electrocardiogram after epinephrine test dose in spinal anesthetized adults
}

\author{
Jeong Woo Lee, Deokyu Kim, Hyun Ho Choi, and Dong Chan Kim \\ Department of Anesthesiology and Pain Medicine, Chonbuk National University Medical School, Jeonju, Korea
}

Background: This study evaluated the efficacy of a T-wave change after the IV administration of low dose epinephrine containing the test dose during spinal anesthesia.

Methods: Eighty healthy adults undergoing spinal anesthesia were enrolled in this study. The subjects were divided randomly into the following 4 groups: Group S $(\mathrm{n}=20)$ received $3 \mathrm{ml}$ of normal saline, group $\mathrm{L}(\mathrm{n}=20)$ received $3 \mathrm{ml}$ of $1.0 \%$ lidocaine, group E5 received $3 \mathrm{ml}$ of 1.0\% lidocaine with epinephrine $5 \mu \mathrm{g}$, and group E10 received 3 $\mathrm{ml}$ of $1.0 \%$ lidocaine with epinephrine $10 \mu \mathrm{g}$. The heart rate (HR) and T-wave amplitude were measured with an electrocardiogram and systolic blood pressure (SBP) using a non-invasive method. Positive responses were defined as an increase in $\mathrm{HR} \geq 20 \mathrm{bpm}$ or $\mathrm{SBP} \geq 15 \mathrm{mmHg}$, or a decrease in the T-wave amplitude $\geq 25 \%$.

Results: The sensitivity (Ss), specificity (Sp), positive predictive value (PPV), and negative predictive value (NPV) of the HR increases were $80 \%, 100 \%, 100 \%$, and $83 \%$, respectively, in groups E5 and E10. For the SBP increases, the Ss, Sp, PPV, and NPV were respectively, $55 \%, 100 \%, 100 \%$, and $70 \%$ in group E5, and $80 \%, 100 \%, 100 \%$, and $83 \%$ in group E10. For the $\geq 25 \%$ decrease in T-wave amplitude, Ss, Sp, PPV, and NPV were respectively, $100 \%, 90 \%$, $91 \%$, and $100 \%$ in group E5, and 95\%, 90\%, 90\%, and 95\% in group E10.

Conclusions: These results suggest that a change in the T-wave amplitude is useful for detecting the unintentional IV administration of low dose epinephrine during CSEA. (Korean J Anesthesiol 2010; 58: 351-356)

Key Words: Electrocardiography, Epidural injection, Epinephrine, Lidocaine.

\footnotetext{
Received: December 1, 2009. Revised: 1st, December 26, 2009; 2nd, January 26, 2010. Accepted: February 22, 2010.

Corresponding author: Dong Chan Kim, M.D., Ph.D., Department of Anesthesiology and Pain Medicine, Chonbuk National University Medical School, 634-18, Geumam-dong, Deokjin-gu, Jeonju 561-712, Korea. Tel: 82-63-250-1241, Fax: 82-63-250-1240, E-mail: dckim@chonbuk.ac.kr (c) This is an open-access article distributed under the terms of the Creative Commons Attribution Non-Commercial License (http:// creativecommons.org/licenses/by-nc/3.0/), which permits unrestricted non-commercial use, distribution, and reproduction in any medium, provided the original work is properly cited.
} 


\section{Introduction}

Combined spinal and epidural anesthesia (CSEA) is a regional anesthetic technique that combines the benefits of both spinal and epidural anesthesia. The spinal component provides the rapid onset of a predictable block. The indwelling epidural catheter allows the dose to be titrated to the desired neuroaxial block effect and provide long lasting analgesia [1]. Because of these potential advantages, CSEA is a useful anesthetic technique for Caesarean sections.

However, during CSEA, confirmation of the correct position of the indwelling epidural catheter before the administration of a large quantity of local anesthetic is very important for avoiding life-threatening complications due to intrathecal or intravascular injection of a large quantity of a local anesthetic. To confirm the correct position of the indwelling epidural catheter, a small quantity of a local anesthetic and epinephrine mixture, 'epidural test dose' is administered through an indwelling epidural catheter. The position of the indwelling epidural catheter is then evaluated by observing the patient's response [2]. In 1981, Moore and Batra [3] first demonstrated the clinical value of a mixture of lidocaine $45 \mathrm{mg}$ and epinephrine $15 \mu \mathrm{g}$ as the epidural test dose, which is currently used widely as an epidural test dose.

Recently it was reported that the intravascular injection of simulated epidural test doses containing epinephrine results in a change in the T-wave on an electrocardiogram (ECG) [4-8]. In addition, Tanaka et al. [7] reported that the change in T-wave on ECG was induced by a lower dose of epinephrine than the traditional test dose $(15 \mu \mathrm{g})$. The results of these studies suggest that the incidental intravascular injection of an epinephrinecontaining test dose can be detected by observing the change in the T-wave on ECG. Although the results of these studies were obtained on non-anesthetic patients or general anesthetic patients, it may be inappropriate to apply these to spinal anesthetic patients.

Therefore, this study evaluated the change in T-wave on ECG after the intravascular administration of a lower dose epin- ephrine-containing epidural test dose during spinal anesthesia.

\section{Materials and Methods}

This study was approved by the Hospital Ethics Committee and informed consent from all participating patients was obtained. The subjects were 80 ASA PS I patients, aged 1865 years. The patients were scheduled to undergo spinal anesthesia for elective surgery. None of the patients were taking cardiovascular drugs. The patients were divided into four groups in a randomized and double-blind manner. Group S (n $=20)$ received $3 \mathrm{ml}$ of normal saline. Group $\mathrm{L}(\mathrm{n}=20)$ received $3 \mathrm{ml}$ of $1.0 \%$ lidocaine. Group E5 $(\mathrm{n}=20)$ received $3 \mathrm{ml}$ of $1.0 \%$ lidocaine with epinephrine $5 \mu \mathrm{g}$. Group E10 $(\mathrm{n}=20)$ received $3 \mathrm{ml}$ of $1.0 \%$ lidocaine with epinephrine $10 \mu \mathrm{g}$. Table 1 lists the demographic data and sensory block levels.

All patients arrived at the operating room without premedication. The patients were monitored with ECG using five electrodes, noninvasive blood pressure, and the peripheral saturation of pulse oxymetry. The administration route of the test dose was limited to the forearm veins in all patients. In the case of patients with the IV line in another part of the body, the IV route was secured on the forearm vein. All patients underwent spinal anesthesia with hyperbaric bupivacaine 10-15 mg via a 25-gauge Quincke needle inserted at the L3-4 or L4-5 interspace. The SBP and HR were monitored every 1 minute for the first 10 minutes and every 5 minute until the experiment was started. While monitoring the SBP and HR, the patients received $8 \mathrm{ml} / \mathrm{kg}$ of Ringer's lactate solution. None of the patients required a vasopressor agent because the SBP was reduced to $<80 \mathrm{mmHg}$ before starting the experiment of the simulating IV test dose. The level of block was confirmed by a cold test and pinprick test at 5 and 30 minutes after the intrathecal administration of local anesthetics.

After confirming the block level in the first 30 minutes, the baseline of the SBP was measured and the baseline of the ECG (standard lead II) was printed over 5 seconds. The print was set up as $1.0 \mathrm{mV} / \mathrm{cm}$ and $25 \mathrm{~mm} / \mathrm{s}$. There was no delay in the

Table 1. Demographic Data and the Level of Sensory Block

\begin{tabular}{|c|c|c|c|c|c|}
\hline & $\begin{array}{l}\text { Group S } \\
(\mathrm{n}=20)\end{array}$ & $\begin{array}{l}\text { Group L } \\
(\mathrm{n}=20)\end{array}$ & $\begin{array}{l}\text { Group E5 } \\
(\mathrm{n}=20)\end{array}$ & $\begin{array}{l}\text { Group E10 } \\
(\mathrm{n}=20)\end{array}$ & $P$ \\
\hline Age (yr) & $45.8 \pm 15.5$ & $44.9 \pm 14.4$ & $44.6 \pm 14.5$ & $40.4 \pm 15.7$ & 0.660 \\
\hline $\operatorname{Sex}(M / F)$ & $8 / 12$ & $12 / 8$ & $10 / 10$ & $12 / 8$ & \\
\hline Height $(\mathrm{cm})$ & $162.0 \pm 9.5$ & $165.2 \pm 9.9$ & $164.3 \pm 11.8$ & $168.3 \pm 8.6$ & 0.271 \\
\hline Weight (kg) & $65.3 \pm 9.4$ & $67.7 \pm 9.5$ & $65.4 \pm 8.7$ & $67.9 \pm 11.0$ & 0.742 \\
\hline Cold test (block level) & $6.0(3.95,8)$ & $6.0(3.95,8.05)$ & $6.0(4,9)$ & $6.5(4.95,9.05)$ & 0.151 \\
\hline Pin-prick test (block level) & $8.0(4,10)$ & $8.0(4.95,10.05)$ & $8.0(6,10.05)$ & $9.0(6,10.05)$ & 0.356 \\
\hline
\end{tabular}

Values are mean \pm SD or number. Values of cold test and pin-prick test are median $\left(5^{\text {th }}\right.$ percentile, $95^{\text {th }}$ percentile). Group S: received $3 \mathrm{ml}$ of normal saline, group L: received $3 \mathrm{ml}$ of 1.0\% lidocaine, group E5: received $3 \mathrm{ml}$ of 1.0\% lidocaine with epinephrine $5 \mu \mathrm{g}$, group E10: received $3 \mathrm{ml}$ of $1.0 \%$ lidocaine with epinephrine $10 \mu \mathrm{g}$. 
monitoring waveform and printing waveform on the monitor. A simulated IV test dose was administered for 5 seconds and the ECG was printed over 5 seconds every 20 seconds for the first 2 minutes and at 5 minutes after administering the IV test dose. The size of the T-wave amplitude was measured from the average of three consecutive values based on the amplitudes shown in each printed ECG. In addition, the heart rate was measured from the average of two R-R intervals collected from three consecutive values. The heart rate measured at 3 and 4 minutes were the values on the monitor. The SBP was measured every minute for 5 minutes. In addition, the subjective symptoms of the patients were divided into the symptoms of the central nervous system, such as dizziness, nervousness, and light-headedness and the symptoms of the cardiovascular system including palpitations, chest discomfort, and hot flushes. A positive response to the IV test dose was defined as a $\geq 20$ bpm increase in heart rate or a $\geq 15 \mathrm{mmHg}$ increase in SBP or a $\geq 25 \%$ decrease in T-wave amplitude. The sensitivity, specificity, positive predictive value (PPV) and negative predictive value (NPV) were calculated from results of the response.

The data is reported as the mean $\pm \mathrm{SD}$, but cold test and pinprick test were indicated as the median $\left(5^{\text {th }}\right.$ percentile, $95^{\text {th }}$ percentile). Statistical analysis was performed using software SigmaStat (version 3.0, Jandel Scientific Software). The data was compared using one way ANOVA between the groups and one way repeated measured ANOVA for within a group. If there were any differences, the data was compared using the HolmSidak method for multiple comparisons. A P value $<0.05$ was considered significant.

\section{Results}

There were no differences in the baseline HR, SBP, and T-wave amplitude before administering the IV test dose between the groups (Table 2). In groups $\mathrm{S}$ and $\mathrm{L}$, there was no change in the
HR, SBP, and T-wave amplitude before and after administering the IV test dose. There was no significant difference between the two groups (Fig. 1, 2 and 3).

The IV test dose caused an increase in HR at 20-80 seconds intervals in groups E5 and E10. The maximum increases in groups E5 and E10 were $30 \pm 15 \mathrm{bpm}$ and $28 \pm 10 \mathrm{bpm}$, respectively. There was no significant difference in the changes in HR between groups E5 and E10 $(\mathrm{P}=0.077$, Fig. 1). In addition, the SBP were increased at $2-3$ min intervals after the IV test dose in groups E5 and E10. The maximum increases in groups E5 and E10 were $19 \pm 12 \mathrm{mmHg}$ and $28 \pm 16 \mathrm{mmHg}$, respectively. There was no significant difference in the changes in SBP between groups E5 and E10 ( $\mathrm{P}=0.313$, Fig. 2). The T-wave amplitude was decreased at 20-80 seconds intervals in groups E5 and E10. The maximum decreases were $0.29 \pm 0.20 \mathrm{mV}$ and $0.32 \pm 0.24$

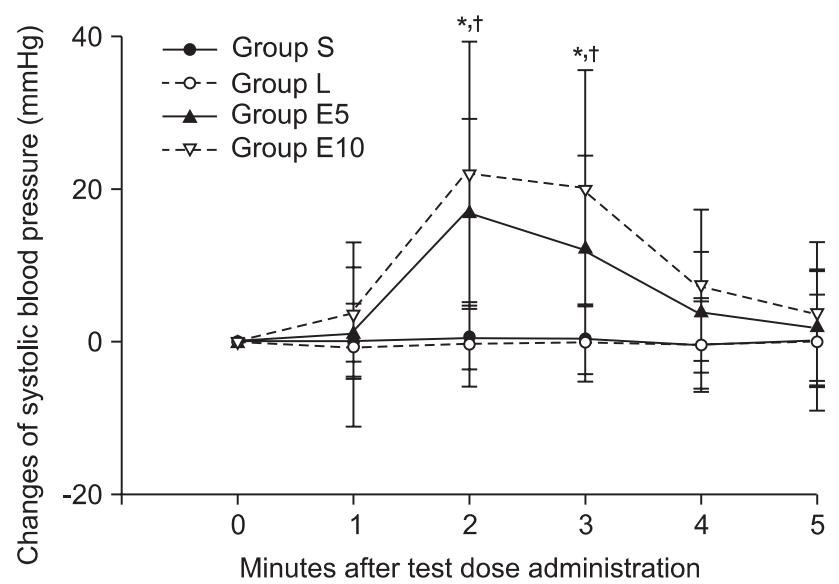

Fig. 1. The changes of heart rate after simulated test dose intravenous administration. Values are mean \pm SD. Group S: received $3 \mathrm{ml}$ of normal saline, group L: received $3 \mathrm{ml}$ of $1.0 \%$ lidocaine, group E5: received $3 \mathrm{ml}$ of $1.0 \%$ lidocaine with epinephrine $5 \mu \mathrm{g}$, group E10: received $3 \mathrm{ml}$ of $1.0 \%$ lidocaine with epinephrine $10 \mu \mathrm{g}$. $* \mathrm{P}<0.05$ compare with baseline values in the group $\mathrm{E} 5,{ }^{\dagger} \mathrm{P}<0.05$ compare with baseline values in the group E10.

Table 2. Baseline Values before Simulated Test Dose and the Maximum Change after Simulated Test Dose

\begin{tabular}{|c|c|c|c|c|c|}
\hline & $\begin{array}{l}\text { Group S } \\
(n=20)\end{array}$ & $\begin{array}{l}\text { Group L } \\
(\mathrm{n}=20)\end{array}$ & $\begin{array}{c}\text { Group E5 } \\
(\mathrm{n}=20)\end{array}$ & $\begin{array}{l}\text { Group E10 } \\
(\mathrm{n}=20)\end{array}$ & $\mathrm{P}$ \\
\hline \multicolumn{6}{|l|}{ HR (bpm) } \\
\hline At baseline & $66 \pm 14$ & $64 \pm 12$ & $64 \pm 9$ & $62 \pm 12$ & 0.789 \\
\hline Maximum change & $67 \pm 14$ & $66 \pm 13$ & $94 \pm 17^{*, \dagger}$ & $90 \pm 12^{*, \dagger}$ & $<0.001$ \\
\hline \multicolumn{6}{|l|}{ SBP (mmHg) } \\
\hline At baseline & $119 \pm 12$ & $125 \pm 18$ & $128 \pm 15$ & $126 \pm 18$ & 0.342 \\
\hline Maximum change & $121 \pm 13$ & $127 \pm 19$ & $147 \pm 19^{*, \dagger}$ & $154 \pm 25^{*, \dagger}$ & $<0.001$ \\
\hline \multicolumn{6}{|l|}{ T-wave Amp (mV) } \\
\hline At baseline & $0.45 \pm 0.33$ & $0.45 \pm 0.26$ & $0.48 \pm 0.33$ & $0.50 \pm 0.23$ & 0.926 \\
\hline Maximum change & $0.42 \pm 0.30$ & $0.40 \pm 0.24$ & $0.19 \pm 0.16^{*, \dagger}$ & $0.18 \pm 0.21^{*, \dagger}$ & $<0.001$ \\
\hline
\end{tabular}

Values are mean \pm SD. HR: heart rate, SBP: systolic blood pressure. Group S: received $3 \mathrm{ml}$ of normal saline, group L: received $3 \mathrm{ml}$ of $1.0 \%$ lidocaine, group E5: received $3 \mathrm{ml}$ of 1.0\% lidocaine with epinephrine $5 \mu \mathrm{g}$, group E10: received $3 \mathrm{ml}$ of $1.0 \%$ lidocaine with epinephrine $10 \mu \mathrm{g}$. Baseline values were no significant differences among the groups. ${ }^{*} \mathrm{P}<0.05$ compare with baseline value, ${ }^{\dagger} \mathrm{P}<0.05$ compare with group $\mathrm{S}$ and group $\mathrm{L}$. 


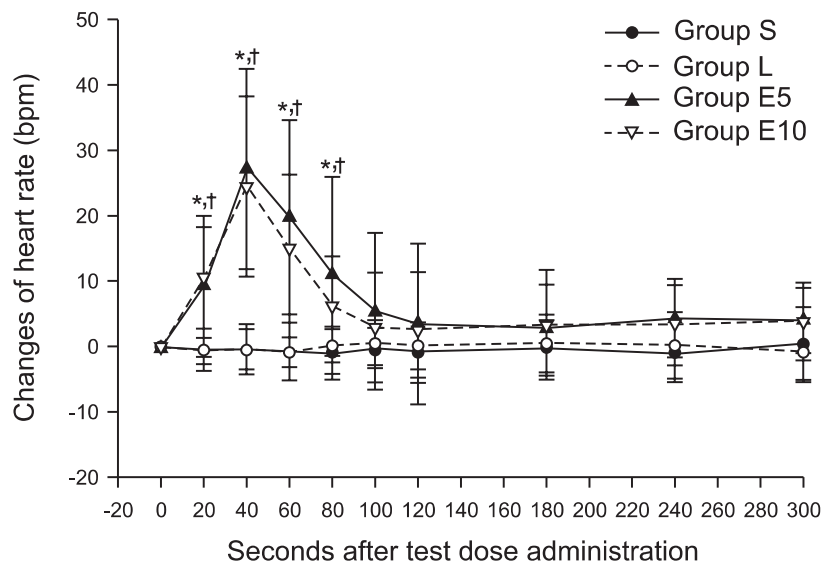

Fig. 2. The changes of systolic blood pressure after simulated test dose intravenous administration. Values are mean \pm SD. Group $\mathrm{S}$ : received $3 \mathrm{ml}$ of normal saline, group L: received $3 \mathrm{ml}$ of $1.0 \%$ lidocaine, group E5: received $3 \mathrm{ml}$ of $1.0 \%$ lidocaine with epinephrine $5 \mu \mathrm{g}$, group E10: received $3 \mathrm{ml}$ of $1.0 \%$ lidocaine with epinephrine 10 $\mu \mathrm{g}$. ${ }^{*} \mathrm{P}<0.05$ compare with baseline values in the group E5, ${ }^{\dagger} \mathrm{P}<0.05$ compare with baseline values in the group E10.

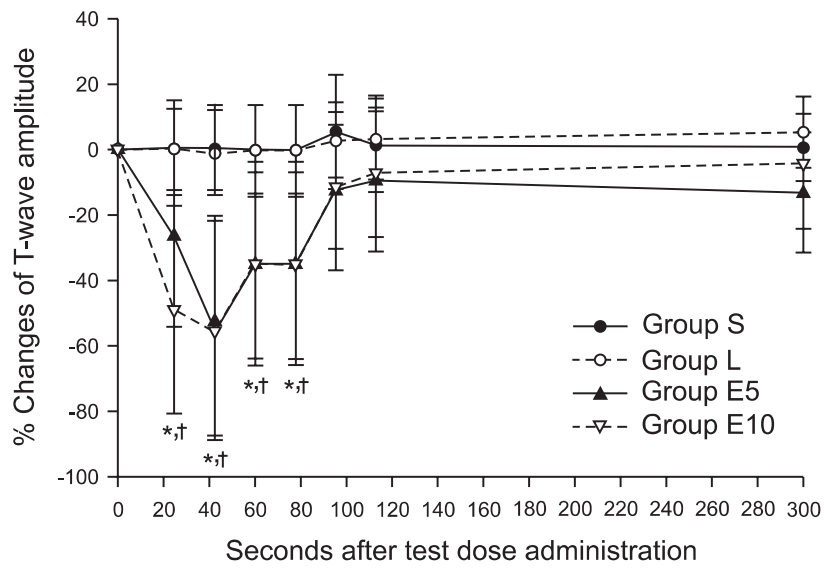

Fig. 3. The percentage changes of T-wave amplitude after simulated test dose intravenous administration. Values are mean \pm SD. Group $\mathrm{S}$ : received $3 \mathrm{ml}$ of normal saline, group $\mathrm{L}$ : received $3 \mathrm{ml}$ of $1.0 \%$ lidocaine, group E5: received $3 \mathrm{ml}$ of $1.0 \%$ lidocaine with epinephrine $5 \mu$ g, group E10: received $3 \mathrm{ml}$ of $1.0 \%$ lidocaine with epinephrine 10 $\mu \mathrm{g} .{ }^{*} \mathrm{P}<0.05$ compare with baseline values in the group E5, ${ }^{\dagger} \mathrm{P}<0.05$ compare with baseline values in the group E10.

$\mathrm{mV}$ respectively. The rate of the decrease was $66 \pm 24 \%$ and $64 \pm$ $34 \%$ respectively. There was no significant difference between groups E5 and E10 (Fig. 3).

Sixteen patients each in groups E5 and E10 showed a $\geq 20$ bpm increase in HR to the IV test doses. None of the patients in groups $\mathrm{S}$ and $\mathrm{L}$ showed $\mathrm{a} \geq 20 \mathrm{bpm}$ increase in HR. Eleven and 16 patients in groups E5 and E10, respectively, showed a $\geq 15 \mathrm{mmHg}$ increase in SBP. None of the patients in groups $\mathrm{S}$ and L showed a $\geq 15 \mathrm{mmHg}$ increase in SBP. Twenty, 19, 1 and 2 patients in groups E5, E10, S and L respectively, showed a
Table 3. Sensitivity, Specificity, and Positive and Negative Predictive Values Based on The Changes of Heart Rate, Systolic Blood Pressure, and T-wave Amplitude for Lidocaine Group

\begin{tabular}{lrr}
\hline & $\begin{array}{c}\text { Group E5 } \\
(\mathrm{n}=20)\end{array}$ & $\begin{array}{r}\text { Group E10 } \\
(\mathrm{n}=20)\end{array}$ \\
\hline By HR ( $\geq 20$ bpm increase) & & \\
Sensitivity & $80 \%$ & $80 \%$ \\
Specificity & $100 \%$ & $100 \%$ \\
Positive predictive value & $100 \%$ & $100 \%$ \\
Negative predictive value & $83 \%$ & $83 \%$ \\
By SBP ( $\geq 15$ mmHg increase $)$ & & \\
Sensitivity & $55 \%$ & $80 \%$ \\
Specificity & $100 \%$ & $100 \%$ \\
Positive predictive value & $100 \%$ & $100 \%$ \\
Negative predictive value & $70 \%$ & $83 \%$ \\
By T-wave amplitude $(\geq 25 \%$ decrease $)$ & & \\
Sensitivity & $100 \%$ & $95 \%$ \\
Specificity & $90 \%$ & $90 \%$ \\
Positive predictive value & $91 \%$ & $90 \%$ \\
Negative predictive value & $100 \%$ & $95 \%$ \\
By combination of T-wave amplitude and HR & & \\
Sensitivity & $100 \%$ & $100 \%$ \\
Specificity & $90 \%$ & $90 \%$ \\
Positive predictive value & $91 \%$ & $91 \%$ \\
Negative predictive value & $100 \%$ & $100 \%$ \\
By combination of T-wave amplitude and SBP & & \\
Sensitivity & $100 \%$ & $100 \%$ \\
Specificity & $90 \%$ & $90 \%$ \\
Positive predictive value & $91 \%$ & $91 \%$ \\
Negative predictive value & $100 \%$ & $100 \%$ \\
\hline
\end{tabular}

HR: heart rate, SBP: systolic blood pressure. Group E5: received $3 \mathrm{ml}$ of $1.0 \%$ lidocaine with epinephrine $5 \mu \mathrm{g}$, group E10: received $3 \mathrm{ml}$ of $1.0 \%$ lidocaine with epinephrine $10 \mu \mathrm{g}$.

Table 4. Adverse Effects after Simulated Test Dose Intravenous Administration

\begin{tabular}{lcc}
\hline & CNS symptoms & C-V symptoms \\
\hline Group S $(\mathrm{n}=20)$ & 0 & 0 \\
Group L $(\mathrm{n}=20)$ & 0 & 0 \\
Group E5 $(\mathrm{n}=20)$ & 3 & $7^{*}$ \\
Group E10 $(\mathrm{n}=20)$ & 4 & $8^{*}$ \\
\hline
\end{tabular}

Values are numbers of patient. CNS symptoms: dizziness, nervousness, and vacantness, C-V symptoms: palpitation, chest discomfort, and facial flushing. Group S: received $3 \mathrm{ml}$ of normal saline, group $\mathrm{L}$ : received $3 \mathrm{ml}$ of $1.0 \%$ lidocaine, group E5: received $3 \mathrm{ml}$ of $1.0 \%$ lidocaine with epinephrine $5 \mu \mathrm{g}$, group E10: received $3 \mathrm{ml}$ of $1.0 \%$ lidocaine with epinephrine $10 \mu \mathrm{g}$. $* \mathrm{P}<0.05$ compare with group $\mathrm{S}$.

$\geq 25 \%$ decrease in baseline T-wave amplitude. Table 3 lists the sensitivity, specificity, PPV, and NPV for the changes in the HR, SBP, and T-wave amplitude.

Three and 4 patients in groups E5 and E10, respectively, complained of central nervous symptoms. Eight and 7 patients in groups E5 and E10, respectively, complained cardiovascular symptoms. The most common symptom was chest discomfort followed by palpitations, dizziness, and nerve uneasiness (Table 4). 


\section{Discussion}

These results showed that the index of the T-wave amplitude on ECG can be used to detect the incidental IV injection of a simulated test dose containing low dose epinephrine in spinal anesthesia.

The hemodynamic response of the epinephrine-containing test dose can be affected by several factors. The factors that may inhibit the increase in heart rate were aging [9], $\beta$-blockers [10], general anesthesia with using sevoflurane [11], and sedation using midazolam and fentanyl [12]. However, the increase in systolic blood pressure may be not suppressed. In the case of general anesthesia with isoflurane, the increase in heart rate and blood pressure can be suppressed $[13,14]$.

Based on these results, an index of $\mathrm{a} \geq 25 \%$ decrease in T-wave amplitude was more useful and superior to the hemodynamic index. Although the sensitivity, specificity and positive and negative predictive values of the hemodynamic index were $55-100 \%$, the index of the T-wave amplitude in groups E5 and E10 was $90-100 \%$. Only one patient in group E10 among epinephrine-injected groups showed a $\leq 25 \%$ decrease in the T-wave amplitude. This patient had a positive hemodynamic index. Therefore, it is believed that we can evaluate the IV injection of the test dose more accurately if the index of a T-wave decrease is used together with the hemodynamic index.

The mechanism of the decrease in T-wave amplitude by epinephrine is unclear. However, it appears to occur by hypokalemia or the activation of $\beta$-adrenaline receptors [15-17]. Stimulation of the sympathetic nervous system causes an increase in the secretion of endogenous catecholamine, which causes a change in the T-wave amplitude [18-20].

Hypokalemia can be caused by the influx of plasma potassium into a cell after stimulation of the $\beta$-adrenaline receptors by epinephrine. However, the period of administering epinephrine in this experiment was shortened to 5 seconds and the T-wave amplitude was changed temporarily. Therefore, the change of T-wave amplitude may not be due to hypokalemia but to the stimulation of $\beta$-adrenaline receptors within the heart.

There was one patient in the saline group and 2 patients in the lidocaine group who showed a $\geq 25 \%$ decrease of T-wave amplitude, which has not been reported. Normally, the T-wave amplitude is decreased by epinephrine and recovered along with a regular pattern. However, there were irregular patterns of the T-wave showed in 3 patients in each measuring moments. In the case when the amplitude of the T-wave is $<0.3 \mathrm{mV}$, it appears to decrease more than $25 \%$ even though it is only decreased slightly. Therefore, it is believed that the regular pattern of change will be more important than the size of the T-wave amplitude.

There were some limitations in the index of the T-wave amplitude. It is difficult to measure the change in the T-wave size in the case of showing an abnormal T-wave or small T-wave. In addition, it can be difficult to evaluate visually because most of the normal T-waves are $<0.5 \mathrm{mV}$ and the ECG can be altered by movement due to breathing [7]. Therefore, the T-wave needs to be observed by increasing the scale of ECG, and by printing and calculating the changes in ECG in order to apply the T-wave index. More study on the change in T-wave with monitoring instead of the printed ECG will be needed. In addition, unlike anesthesia in adults, the change in the T-wave of children is not useful as a marker for accidental intravascular injection [5].

Three and 4 patients in groups E5 and E10, respectively, complained of dizziness, nervousness, and light-headedness caused by the administration of epinephrine. Seven and 8 patients in groups E5 and E10, respectively, complained of palpitations, chest discomfort, and hot flush. In addition, 6 and 5 patients in groups E5 and E10, respectively, showed an increase in the maximum instantaneous heart rate by more than $100 \mathrm{bpm}$. In particular, there was one patient who had a $>130 \mathrm{bpm}$ increase. There were 3 patients in group E10 who showed an increase in systolic blood pressure to more than 180 mmHg. However, all of the changes in the index were recovered within 3 minutes. The symptoms of the central nerve system and cardiovascular system were also temporary.

There was no statistical difference in the index of decreasing T-wave amplitude between E5 and E10. Therefore, the T-wave amplitude can be changed with $<5 \mu$ g of epinephrine used in the epidural test dose. However, it is believed that it will be difficult to apply in a clinical setting. It was assumed that the entire epidural test dose through the epidural catheter had been administered into blood vessels without any loss. However, it is unclear if the full epidural test dose is administered into blood vessel through an epidural catheter in a real situation. Like in this case, only epinephrine $5 \mu \mathrm{g}$ as the epidural test dose cannot be sufficient to cause a change in the T-wave after the unintentional IV administration of epinephrine. Therefore, further studies will be needed to prove the efficacy of the T-wave amplitude in cases of $<5 \mu$ g of epinephrine because the decrease in T-wave size in this study was not proportional to the dose of epinephrine.

In conclusion, the change in T-wave in spinal anesthesia may be clinically useful to detect an unintentional intravascular injection of low dose epinephrine containing an epidural test dose in CSEA. However, further studies will be needed to determine the suitable test dose of epinephrine.

\section{References}

1. Coates MB. Combined subarachnoid and epidural techniques. Anaesthesia 1982; 37: 89-90. 
2. Kim JY, Kwon JY, Kim HK, Baik SW, Kim IS, Chung KS. The efficacy of epinephrine test doses during combined spinal-epidural anesthesia in adult patients. Korean J Anesthesiol 1999; 36: 625-31.

3. Moore DC, Batra MS. The components of an effective test dose prior to epidural block. Anesthesiology 1981; 55: 693-6.

4. Tanaka M, Nishikawa T. A comparative study of hemodynamic and T-wave criteria for detecting intravascular injection of the test dose (epinephrine) in sevoflurane- anesthetized adults. Anesth Analg 1999; 89: 32-6.

5. Freid EB, Bailey AG, Valley RD. Electrocardiographic and hemodynamic changes associated with unintentional intravascular injection of bupivacaine with epinephrine in infants. Anesthesiology 1993; 79: 394-8.

6. Tanaka M, Nishikawa T. T-wave amplitude as an indicator for detecting intravascular injection of epinephrine test dose in awake and anesthetized elderly patients. Anesth Analg 2001; 93: 1332-7.

7. Tanaka M, Goyagi T, Kimura T, Nishikawa T. The efficacy of hemodynamic and $\mathrm{T}$ wave criteria for detecting intravascular injection of epinephrine test doses in anesthetized adults: a dose-response study. Anesth Analg 2000; 91: 1196-202.

8. Takahashi S, Tanaka M, Toyooka H. The efficacy of hemodynamic and T-wave criteria for detecting intravascular injection of epinephrine test dose in propofol-anesthetized adults. Anesth Analg 2002; 94: 717-22.

9. Guinard JP, Mulroy MF, Carpenter RL. Aging reduces the reliability of epidural epinephrine test doses. Reg Anesth 1995; 20: 193-8.

10. Guinard JP, Mulroy MF, Carpenter RL, Knopes KD. Test doses: optimal epinephrine content with and without acute beta-adrenergic blockade. Anesthesiology 1990; 73: 386-92.

11. Takahashi S, Tanaka M. Reduced efficacy of simulated epidural test doses in sevoflurane-anesthetized adults. Can J Anaesth 1999; 46: 433-8.

12. Tanaka M, Sato M, Kimura T, Nishikawa T. The efficacy of simulated intravascular test dose in sedated patients. Anesth Analg 2001; 93: 1612-7.

13. Tanaka M, Takahashi S, Kondo T, Matsumiya N. Efficacy of simulated epidural test doses in adult patients anesthetized with isoflurane: a dose-response study. Anesth Analg 1995; 81: 987-92.

14. Liu SS, Carpenter RL. Hemodynamic responses to intravascular injection of epinephrine-containing epidural test doses in adults during general anesthesia. Anesthesiology 1996; 84: 81-7.

15. Hahn RG, Löfgren A. Epinephrine, potassium and the electrocardiogram during regional anaesthesia. Eur J Anaesthesiol 2000; 17: $132-7$.

16. Kubota Y, Toyoda Y, Kubota H, Asada A. Epinephrine in local anesthetics does indeed produce hypokalemia and ECG changes. Anesth Analg 1993; 77: 867-8.

17. Reid JL, Whyte KF, Struthers AD. Epinephrine-induced hypokalemia: the role of beta adrenoceptors. Am J Cardiol 1986; 57: 23F-27F.

18. Guazzi M, Fiorentini C, Polese A, Magrini F, Olivari MT. Stress-induced and sympathetically-mediated electrocardiographic and circulatory variations in the primary hyperkinetic heart syndrome. Cardiovasc Res 1975; 9: 342-54.

19. Atterhög JH, Eliasson K, Hjemdahl P. Sympathoadrenal and cardiovascular responses to mental stress, isometric handgrip, and cold pressor test in asymptomatic young men with primary $\mathrm{T}$ wave abnormalities in the electrocardiogram. Br Heart J 1981; 46: 311-9.

20. Breslow MJ, Miller CF, Parker SD, Walman AT, Rogers MC. Changes in T-wave morphology following anesthesia and surgery: a common recovery-room phenomenon. Anesthesiology 1986; 64: 398-402. 